\title{
Short communication: Effect of blackberry and pomegranate oils on vaccenic acid formation in a single-flow continuous culture fermentation system
}

\author{
A. Ishlak, ${ }^{*}$ A. A. AbuGhazaleh, ${ }^{* 1}$ and M. Günal† \\ *Department of Animal Science, Food and Nutrition, Southern Illinois University, Carbondale 62901 \\ †Department of Animal Science, Süleyman Demirel University, Isparta, 32260, Turkey
}

\begin{abstract}
A single-flow continuous culture fermenter system was used to study the effect of blackberry and pomegranate oils on vaccenic acid (trans-11 C18:1; VA) formation. Four continuous culture fermenters were used in a $4 \times$ 4 Latin square design with 4 periods of $10 \mathrm{~d}$ each. Diets were (1) control (CON), (2) control plus soybean oil (SBO), (3) control plus blackberry oil (BBO), and (4) control plus pomegranate oil (PMO). Oil supplements were added at $30 \mathrm{~g} / \mathrm{kg}$ of diet dry matter. Effluents were collected from each fermenter during the last 3 $\mathrm{d}$ of each period and analyzed for nutrient and fatty acid composition. The concentration of VA in effluents increased with oil supplements and was greatest with the $\mathrm{BBO}$ diet. The concentration of stearic acid (C18:0) increased with the addition of soybean oil but decreased with the addition of pomegranate oil compared with the CON diet. The concentration of cis-9,trans-11 conjugated linoleic acid increased with oil supplements and was greatest with the PMO diet. In conclusion, all 3 oil sources were effective in increasing the production of VA. The effect of PMO and BBO on VA may have resulted in part from inhibition of the final step in the biohydrogenation of VA to stearic acid.
\end{abstract}

Key words: soybean oil, blackberry oil, pomegranate oil, trans fatty acids

\section{Short Communication}

Conjugated linoleic acids (CLA) are naturally occurring fatty acids in foods derived from ruminants. Conjugated FA have recently attracted significant attention because of their health benefits in a variety of models of metabolic and chronic inflammatory diseases. Among the many CLA isomers, cis-9,trans-11 (c9t11) and trans-10,cis-12 CLA have received the most attention because of their recognized potential health benefits (Crumb, 2011; Tanaka et al., 2011). The c9t11 CLA is

Received March 27, 2013.

Accepted October 26, 2013.

${ }^{1}$ Corresponding author: aabugha@siu.edu synthesized either in the rumen as an intermediate during the biohydrogenation of linoleic acid (Harfoot and Hazlewood, 1997) and linolenic acid (Lee and Jenkins, 2011 ) or in tissues by $\Delta^{9}$-desaturase from vaccenic acid (trans-11 C18:1; VA), another important intermediate in ruminal biohydrogenation of C18 unsaturated FA (Griinari and Bauman, 1999). Bichi et al. (2012) estimated that more than $74 \%$ of $c 9 t 11$ CLA in milk fat is synthesized through the activity of the $\Delta^{9}$-desaturase enzyme; therefore, increasing VA flow from the rumen to the lower digestive tract would be necessary to increase milk $c 9 t 11$ CLA content.

Previous studies have demonstrated an increase in VA flow from the rumen with the feeding of plant oils high in C18 unsaturated FA (AbuGhazaleh and Buckles, 2007; Varadyovaet al., 2007) or fish oil (Lee et al., 2008; Potu et al., 2011). Plant oils high in unsaturated C18 FA increase the availability of VA precursors in the rumen, whereas the effect of fish oil is believed to occur because of the inhibitory effect of docosahexaenoic acid (C22:6n-3) in fish oil on the reduction of VA to stearic acid (AbuGhazaleh and Jenkins, 2004). Pomegranate and blackberry oils are characterized by their high C18 unsaturated FA content. Fang et al. (2012) compared the FA composition in the seed oil of 4 blackberry varieties and reported that linoleic acid was the main FA (from 51.7 to $69.3 \%$ of total FA) followed by linolenic acid (from 10.6 to $31.6 \%$ of total FA). Kyralan et al. (2009) also compared the FA composition of 15 different pomegranate seeds and reported that punicic acid (C18:3 cis-9,trans-11,cis-13) was the predominant FA in pomegranate oil, accounting for 74.4 to $76.2 \%$ of total FA. Recently, Modaresi et al. (2011) reported an increase in milk $c 9 t 11$ CLA content when goat diet was supplemented with pomegranate seed pulp. Pomegranate and blackberry seeds are also rich in polyphenolic compounds (proanthocyanidins, hydrolyzable tannins, and flavonols) that have potent antioxidant and antimicrobial properties (Wang et al., 2004; Dahham et al., 2010). During cold processing, these compounds are extracted into the cold pressed oil in significant quantities (Parry and $\mathrm{Yu}, 2004)$. 
Table 1. Ingredient, chemical and fatty acid composition of treatment diets

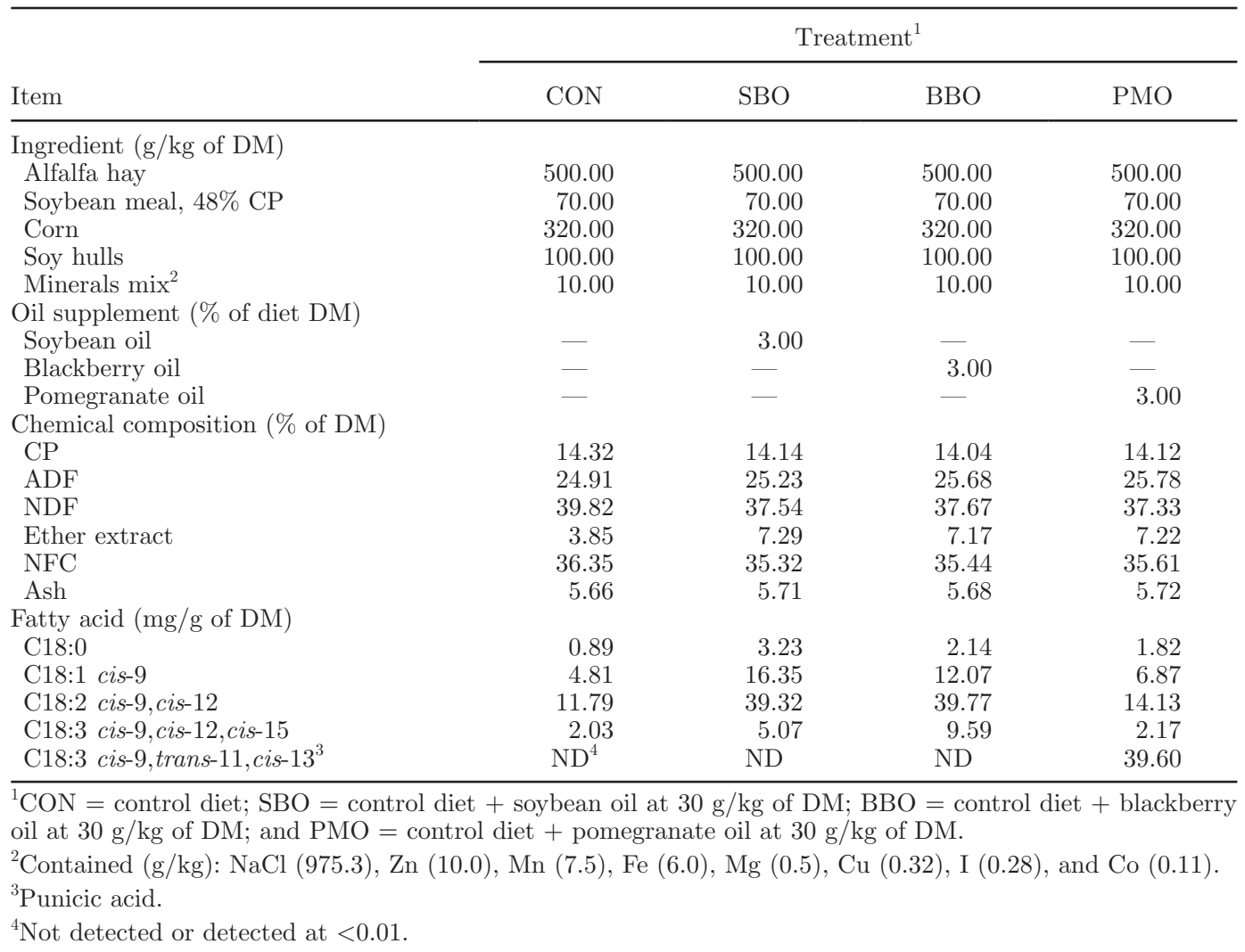

To our knowledge, the effects of pomegranate and blackberry oils on VA formation have not been investigated. Therefore, the main objective of this study was to compare the effects of 3 oil sources high in $\mathrm{C} 18$ unsaturated FA (soybean, blackberry, and pomegranate oils) on VA formation in a continuous culture system.

Four single continuous culture fermenters, as described by Teather and Sauer (1988), were used in 4 $\times 4$ Latin square designs with 4 periods of $10 \mathrm{~d}$ each. The first $7 \mathrm{~d}$ were used for adaptation and the last 3 d for sample collection. Treatment diets (50:50 forage: concentrate ratio; DM basis) were fed at $45 \mathrm{~g} / \mathrm{d}$ (DM basis) in 3 equal portions during the day at 0800, 1500, and $2200 \mathrm{~h}$. Diets were (1) control (CON), (2) control plus soybean oil (SBO), (3) control plus blackberry oil (BBO), and (4) control plus pomegranate oil (PMO). The forage consisted of alfalfa pellets, and the concentrate mix contained corn, soybean meal, soy hulls, and minerals (Table 1). Oil supplements were added at 30 $\mathrm{g} / \mathrm{kg}$ of diet DM. Cold-pressed blackberry oil $(57.4 \%$ linoleic acid, $18.0 \%$ linolenic acid) and pomegranate oil (75.9\% punicic acid, $5.4 \%$ linoleic acid) were purchased from Botanic Innovations LLC (Spooner, WI), whereas the soybean oil ( $52.8 \%$ linoleic acid, $6.3 \%$ linolenic acid) was purchased from a local store.
Two ruminally fistulated Holstein cows fed a TMR (55:45 forage: concentrate ratio; DM basis) were used for collection of ruminal contents. Whole ruminal contents were collected approximately $4 \mathrm{~h}$ after the morning feeding and then immediately transferred to the laboratory in sealed bags. Samples were then strained using a double-layered cheese cloth, and approximately $600 \mathrm{~mL}$ of the ruminal fluid was added to each of the 4 fermenters, containing $100 \mathrm{~mL}$ of prewarmed buffer. Cultures were stirred (BCD Caframo Stirrer, Fisher, St. Louis, MO) continuously at $45 \mathrm{rpm}$, and fermenter $\mathrm{pH}$ was measured daily before addition of feed using a portable pH meter at 0800,1500 , and $2400 \mathrm{~h}$. Anaerobic conditions in fermenters were maintained by infusing $\mathrm{CO}_{2}$ at $40 \mathrm{~mL} / \mathrm{min}$ and fermenter temperature was maintained at $39^{\circ} \mathrm{C}$ using a circulating water bath. The buffer solution (Weller and Pilgrim, 1974) was prepared in one container and delivered continuously to each fermenter at a flow rate of $1.16 \mathrm{~mL} / \mathrm{min}\left(0.10 \mathrm{~h}^{-1}\right.$ liquid dilution rate), using a precision pump. The flow rate of each fermenter was recorded every day at $0800 \mathrm{~h}$.

On d 8, 9, and 10 of each period, the overflow (effluent) was collected into 2 -L plastic flasks immersed in ice. The collected effluents from each fermenter during the last $3 \mathrm{~d}$ were then homogenized by stirring and $25 \%$ 
subsamples were pooled into one sample and stored at $-20^{\circ} \mathrm{C}$ until further analysis for nutrient degradation, VFA, and FA profiles as described by AbuGhazaleh and Buckles (2007) and Potu et al. (2011). Differences between nutrients intake and outflow were used to estimate degradation. Rumen microbes associated with overflow samples were separated by centrifugation at $500 \times g$ for 15 min at $4^{\circ} \mathrm{C}$, as described by AbuGhazaleh et al. (2011).

Data were analyzed as a $4 \times 4$ Latin square design using the generalized linear model (GLM) of SAS (SAS Institute Inc., Cary, NC). The statistical model included fermenters, diet, and period. Fixed effects were diet and period, and the random effect was fermenter. Means were compared using the Tukey test. Results are expressed as least squares means with standard error of the means. The significance threshold was set at $P$ $<0.05$.

The apparent degradability of DM $(67.5,63.9,65.9$, and $66.4 \%)$ and $\operatorname{NDF}(45.3,51.5,47.5$, and $49.7 \%)$ and the concentration of total VFA $(61.49,58.18,55.16$, and $56.79 \mathrm{mM}$ ) for the CON, SBO, BBO, and PMO diets, respectively, were not affected $(P>0.05)$ by treatment. In addition, the proportions of acetate (35.7, 35.8, 35.2, and $36.2 \%$ of total VFA), propionate $(29.9,27.4,28.4$, and $27.5 \%$ of total VFA), and butyrate $(20.9,22.2,24.3$, and $25.4 \%$ of total VFA) and fermenter $\mathrm{pH}(6.51,6.53$, 6.57, and 6.53) for the CON, SBO, BBO and PMO diets, respectively, were not affected $(P>0.05)$ by oil supplements.

The concentrations of VA in effluent increased with all oil supplements with the greatest increase being in the BBO diet (Table 2). Previous studies have also reported increases in VA concentration in effluent (AbuGhazaleh and Buckles, 2007; Potu et al., 2011) and duodenal (Loor et al., 2004; Kucuk et al., 2008) samples when diets were supplemented with oils. Despite the relatively equal supply of linoleic acid between the $\mathrm{SBO}$ and $\mathrm{BBO}$ diets, the concentration of VA was greater and that of stearic acid was lower with the $\mathrm{BBO}$ diet, suggesting that the increase in VA concentration with the $\mathrm{BBO}$ diet resulted in part because of the incomplete reduction of VA into stearic acid. The addition of pomegranate oil also increased the concentration of VA, suggesting that punicic acid may also serve as a precursor for VA. The pathway of biohydrogenation for punicic acid has not been described before, but it most likely involves the formation of $c 9 \mathrm{t} 11$ CLA and VA as the major decanoic and octadecanoic intermediates, respectively, as the increase in $c 9 t 11$ CLA was also greatest with the PMO diet. Modaresi et al. (2011) reported an increase in milk VA and $c 9$ t11 CLA content when goat diets were supplemented with pomegranate seed pulp at $12 \%$ of diet DM. In contrast to that observed in the SBO diet, the increase in VA concentration with the PMO diet was at the expense of stearic acid, suggesting that active compound(s) in pomegranate oil inhibited the terminal step of biohydrogenation - the reduction of VA to stearic acid. The inhibitory effects of pomegranate oil on the terminal step of biohydrogenation may have resulted, therefore, from the effect of punicic acid, its derivatives, or other active compound(s) on rumen microbes responsible for the terminal step of biohydrogenation. Pomegranate and blackberry products have potent antioxidant and antimicrobial properties, which are attributed to their high content of polyphenols such as hydrolyzable tannins (punicalin, pedunculagin, punicalagin, ellagitannins, and gallotannins) and flavonols (quercetin, kaempferol, and luteolin glycosides) (Dahham et al., 2010; Chirumbolo, 2011). In in vitro studies, Vasta et al. (2009) and Khiaosa-Ard et al. (2009) reported that tannin caused significant reductions in the concentration of stearic acid along with significant increases in VA accumulation. However, Toral et al. (2011) reported no change in milk stearic acid content but an increase in VA content when ewes were fed an extract of quebracho tannins at $20 \mathrm{~g} / \mathrm{kg}$ of DM. Cabiddu et al. (2009) also reported an increase in milk VA but no changes in milk stearic acid content in sheep grazed on a plant rich in condensed tannins (flowering sulla). Similarly, Vasta et al. (2010) reported an increase in VA concentration in the rumen but no change in stearic acid concentration in sheep fed quebracho tannins.

Previous studies have reported partial and sometimes complete inhibition of the terminal reduction step in biohydrogenation (C18:1 to stearic acid) when diets were supplemented with FO (AbuGhazaleh and Jenkins, 2004; Potu et al., 2011), algae (Toral et al., 2012), or monensin (Fellner et al., 1997). Recent studies have associated the effects of fish oil and algae on VA accumulation with changes in the rumen bacterial composition. Potu et al. (2011), Gudla et al. (2012), and AbuGhazaleh and Ishlak (2013) reported significant reductions in DNA abundance for Butyrivibrio fibrisolvens, Butyrivibrio-VA subgroup, Butyrivibriostearic acid subgroup, Butyrivibrio proteoclasticus, and Ruminococcus albus when diets were supplemented with fish oil. Additionally, Jami et al. (2012) reported decreases in the rumen abundance of $B$. fibrisolvens, $R$. albus, and Fibrobacter succinogenes when dairy cow diets were supplemented with concentrated pomegranate residue extract; the authors attributed this negative effect to the polyphenolic compounds found in pomegranate extract. In the present study, polyphenolic and antioxidant compounds in pomegranate and blackberry oil may also have had a negative effect on microbial growth. It is widely accepted that polyphenolic com- 
Table 2. The effect of treatment diets on effluent fatty acids

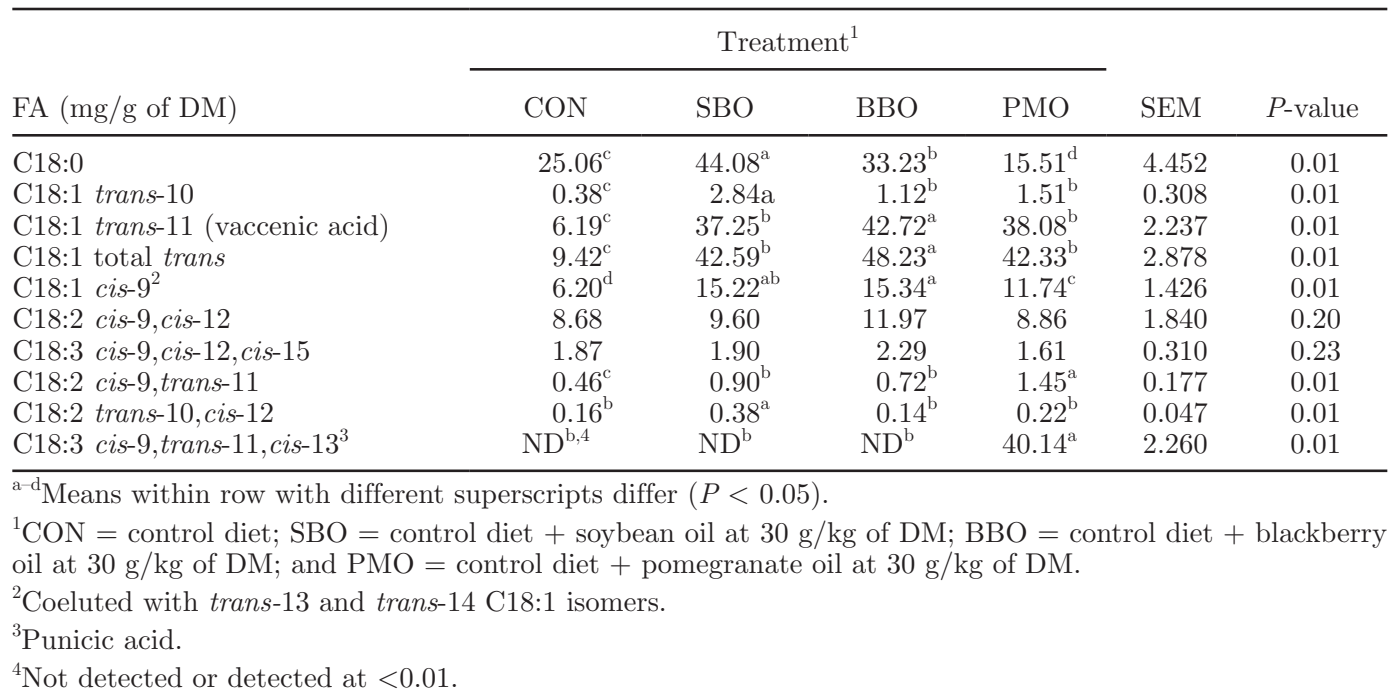

pounds, especially tannic compounds, are able to bind proteins and inhibit the growth of ruminal bacteria (Min et al., 2003; Chirumbolo, 2011). Jones et al. (1994) reported that tannins from Onobrychis viciifolia induced morphological changes and reduced the growth iof B. fibrisolvens. Durmic et al. (2008) reported a reduction in the proliferation of $B$. proteoclasticus $\mathrm{B} 316 \mathrm{~T}$ and B. proteoclasticus $\mathrm{P} 18$ when extracts from Acacia iteaphylla, which contains condensed tannins, were incubated in vitro with sheep ruminal fluid. Khiaosa-Ard et al. (2009) also associated the accumulation of VA in rumen cultures with tannin extract feeding with reductions in protozoal counts and a compensatory increase in bacterial count.

The greater concentration of $c 9 t 11$ CLA in effluents of oil-supplemented diets compared with the CON diet is consistent with the findings of others (Gomez-Cortes et al., 2008; Potu et al., 2011). The increase in $c 9 t 11$ CLA with the SBO and BBO diets was primarily a function of linoleic acid intake because $c 9 t 11$ CLA in the rumen is formed as an intermediate during the biohydrogenation of linoleic acid (Harfoot and Hazlewood, 1997). The greater increase in $c 9 t 11$ CLA concentration with the PMO diet indicates that the biohydrogenation pathway for punicic acid involves c9t11 CLA as the major intermediate. The increased $c 9 t 11$ CLA with PMO diet may have also resulted from a delay in the c9t11 CLA reduction step; c9t11 CLA is known to be a transient intermediate during the biohydrogenation of linoleic acid and therefore any delays in its reduction has the potential to increase its flow from the fermenters. Vlaeminck et al. (2008) and Boeckaert et al. (2007) reported that addition of docosahexaenoic acid to rumen cultures resulted in accumulation of $c 9 t 11$ CLA and other trans C18:1 during the first $6 \mathrm{~h}$ of incubation, but not after $24 \mathrm{~h}$. It is possible therefore that the active compounds in pomegranate oil slowed the reduction of $c 9 t 11$ CLA to VA.

In conclusion, the concentration of VA in effluents increased with oil supplements and the increase was greatest with blackberry oil. The effects of pomegranate and blackberry oils on VA formation resulted in part from inhibition of the terminal reduction step of biohydrogenation, perhaps by affecting the bacteria responsible for the reduction of VA to stearic acid. Further research is needed to identify the active compounds in pomegranate and blackberry oils responsible for the effects on biohydrogenation.

\section{REFERENCES}

AbuGhazaleh, A. A., S. Abo-El-Nor, and S. A. Ibrahim. 2011. The effect of replacing corn with glycerol on ruminal bacteria in continuous culture fermenters. J. Anim. Physiol. Anim. Nutr. (Berl.) 95:313-319.

AbuGhazaleh, A. A., and W. R. Buckles. 2007. The effect of solid dilution rate and lipid source on trans-C18:1 and conjugated linoleic acid production by ruminal microbes in continuous culture. J. Dairy Sci. 90:963-969.

AbuGhazaleh, A. A., and A. Ishlak. 2013. Effects of incremental amounts of fish oil on trans fatty acids and Butyrivibrio bacteria in continuous culture fermenters. J. Anim. Phys. Anim. Nutr. http://dx.doi.org/10.1111/.jpn.12077.

AbuGhazaleh, A. A., and T. C. Jenkins. 2004. Short communication: Docosahexaenoic acid promotes vaccenic acid accumulation in mixed ruminal cultures when incubated with linoleic acid. J. Dairy Sci. 87:1047-1050.

Bichi, E., P. G. Toral, G. Hervás, P. Frutos, P. Gómez-Cortés, M. Juárez, and M. A. de la Fuente. 2012. Inhibition of $\Delta^{9}$-desaturase activity with sterculic acid: Effect on the endogenous synthesis of cis-9 18:1 and cis-9,trans-11 18:2 in dairy sheep. J. Dairy Sci. 95:5242-5252.

Boeckaert, C., B. Vlaeminck, J. Mestdagh, and V. Fievez. 2007. In vitro examination of DHA-edible micro algae. 1. Effect on rumen lipolysis and biohydrogenation of linoleic and linolenic acids. Anim. Feed Sci. Technol. 136:63-79. 
Cabiddu, A., G. Molle, M. Decandia, S. Spada, M. Fiori, G. Piredda, and M. Addis. 2009. Responses to condensed tannins of flowering sulla (Hedysarum coronarium L.) grazed by dairy sheep. Part 2: Effects on milk fatty acid profile. Livest. Sci. 123:230-240.

Chirumbolo, S. 2011. Plant polyphenolic compounds as potential antimicrobial drugs. J. Med. Microbiol. 60:1562-1563.

Crumb, D. J. 2011. Conjugated linoleic acid (CLA) - An overview. Int. J. Appl. Res. Nat. Prod. 4:12-18.

Dahham, S. S., M. N. Ali, H. Tabassum, and M. Khan. 2010. Studies on antibacterial and antifungal activity of pomegranate (Punica granatum L.). Am.-Euras. J. Agric. Environ. Sci. 9:273-281.

Durmic, Z., C. S. McSweeney, G. W. Kemp, P. P. Hutton, R. J. Wallace, and P. E. Vercoe. 2008. Australian plants with potential to inhibit bacteria and processes involved in ruminal biohydrogenation of fatty acids. Anim. Feed Sci. Technol. 145:271-284.

Fang, L., W. Wu, H. Zhao, L. Iv, and W. Li. 2012. Characteristics of feed oils from four blackberries varieties (Rubus L.). Appl. Mech. Mater. 140:273-277.

Fellner, V., F. D. Sauer, and J. Kramer. 1997. Effect of nigericin, monensin, and tetronasin on biohydrogenation in continuous flowthrough ruminal fermenters. J. Dairy Sci. 80:921-928.

Gómez-Cortés, P., P. Frutos, A. R. Mantecon, M. Juarez, M. A. De la Fuente, and G. Hervas. 2008. Milk production, conjugated linoleic acid content, and in vitro ruminal fermentation in response to high levels of soybean oil in dairy ewe diet. J. Dairy Sci. 91:1560-1569.

Griinari, J. M., and D. E. Bauman. 1999. Biosynthesis of conjugated linoleic acid and its incorporation into meat and milk in ruminants. Pages 180-200 in Advances in Conjugated Linoleic Acid Research. Vol. 1. M. P. Yurawecz, M. M. Mossoba, J. K. G. Kramer, M. W. Pariza, and G. J. Nelson, ed. AOCS Press, Champaign, IL.

Gudla, P., A. Ishlak, and A. A. AbuGhazaleh. 2012. The effect of forage level and oil supplement on Butyrivibrio fibrisolvens and Anaerovibrio lipolytica in continuous culture fermenters. Asianaustralas. J. Anim. Sci. 25:234-239.

Harfoot, C. G., and G. P. Hazlewood. 1997. Lipid metabolism in the rumen. Pages 382-426 in Rumen Microbial Ecosystem. P. N. Hobson and C. S. Stewart, ed. Blackie Professional Publ., London, UK.

Jami, E., A. Shabtay, M. Nikbachat, E. Yosef, J. Miron, and I. Mizrahi. 2012. Effects of adding a concentrated pomegranate-residue extract to the ration of lactating cows on in vivo digestibility and profile of rumen bacterial population. J. Dairy Sci. 95:5996-6005.

Jones, G. A., T. A. McAllister, A. D. Muir, and K. J. Cheng. 1994. Effects of sainfoin (Onobrichis viciifolia Scop.) condensed tannins on growth and proteolysis by four strains of ruminal bacteria. Appl. Environ. Microbiol. 60:1374-1378.

Khiaosa-Ard, R., S. F. Bryner, M. R. L. Scheeder, H. R. Wettstein, F. Leiber, M. Kreuzer, and C. R. Soliva. 2009. Evidence for the inhibition of the terminal step of ruminal $\alpha$-linolenic acid biohydrogenation by condensed tannins. J. Dairy Sci. 92:177-188.

Kucuk, T., H. Kozinoglu, and A. Kaba. 2008. Growth hormone cotreatment within a GnRH agonist long protocol in patients with poor ovarian response: A prospective, randomized, clinical trial. J. Assist. Reprod. Genet. 25:123-127.

Kyralan, M., M. Golukcu, and H. Tokgoz. 2009. Oil and conjugated linolenic acid contents of seeds from important pomegranate cultivars (Punica granatum L.) grown in Turkey. J. Am. Oil Chem. Soc. 86:985-990.

Lee, M. R. F., K. J. Shingfield, J. K. Tweed, V. Toivonen, S. A. Huws, and N. D. Scollan. 2008. Effect of fish oil on ruminal biohydrogenation of $\mathrm{C} 18$ unsaturated fatty acids in steers fed grass or red clover silages. Animal 2:1859-1869.
Lee, Y. J., and T. C. Jenkins. 2011. Biohydrogenation of linolenic acid to stearic acid by the rumen microbial population yields multiple intermediate conjugated diene isomers. J. Nutr. 141:1445-1450.

Loor, J. J., K. Ueda, A. Ferlay, Y. Chilliard, and M. Doreau. 2004. Biohydrogenation, duodenal flow, and intestinal digestibility of trans fatty acids and conjugated linoleic acids in response to dietary forage:concentrate ratio and linseed oil in dairy cows. J. Dairy Sci. 87:2472-2485.

Min, B. R., T. N. Barry, G. T. Attwood, and W. C. Mc Nabb. 2003. The effect of condensed tannins on the nutrition and health of ruminants fed fresh temperate forages: A review. Anim. Feed Sci. Technol. 106:3-19.

Modaresi, J., M. H. Fathi Nasri, L. Rashidi, O. Dayani, and E. Kebreab. 2011. Short communication: Effects of supplementation with pomegranate seed pulp on concentrations of conjugated linoleic acid and punicic acid in goat milk. J. Dairy Sci. 94:4075-4080.

Parry, J., and L. Yu. 2004. Fatty acid content and antioxidant properties of cold-pressed black raspberry seed oil and meal. J. Food Sci. 69:189-193.

Potu, R. B. A. A. AbuGhazaleh, D. Hastings, K. Jones, and S. A. Ibrahim. 2011. The effect of lipid supplements on ruminal bacteria in continuous culture fermenters varies with the fatty acid composition. J. Microbiol. 49:216-223

Tanaka, T., M. Hosokawa, Y. Yasui, R. Ishigamori, and K. Miyashita. 2011. Cancer chemopreventive ability of conjugated linolenic acids. Int. J. Mol. Sci. 12:7495-7509.

Teather, R. M., and F. D. Sauer. 1988. A naturally compartmented rumen simulation system for the continuous culture of rumen bacteria and protozoa. J. Dairy Sci. 71:666-673.

Toral, P. G., A. Belenguer, K. J. Shingfield, G. Hervás, V. Toivonen, and P. Frutos. 2012. Fatty acid composition and bacterial community changes in the rumen fluid of lactating sheep fed sunflower oil plus incremental levels of marine algae. J. Dairy Sci. 95:794-806.

Toral, P. G., G. Hervás, E. Bichi, A. Belenguer, and P. Frutos. 2011. Tannins as feed additives to modulate ruminal biohydrogenation: Effects on animal performance, milk fatty acid composition and ruminal fermentation in dairy ewes fed a diet containing sunflower oil. Anim. Feed Sci. Technol. 164:199-206.

Varadyova, Z., S. Kišidayova, P. Siroka, and D. Jalč. 2007. Fatty acid profiles of rumen fluid from sheep fed diets supplemented with various oils and effect on the rumen ciliate population. Czech J. Anim. Sci. 52:399-406.

Vasta, V., D. Yáñez-Ruiz, M. Mele, A. Serra, G. Luciano, M. Lanza, and A. Priolo. 2010. Bacterial and protozoal communities and fatty acid profile in the rumen of sheep fed a diet containing added tannins. Appl. Environ. Microbiol. 76:2549-2555.

Vasta, V., H. Makkar, M. Mele, and A. Priolo. 2009. Ruminal biohydrogenation as affected by tannins in vitro. Br. J. Nutr. 102:8292.

Vlaeminck, B., G. Mengistu, V. Fievez, L. de Jonge, and J. Dijkstra. 2008. Effect of in vitro docosahexaenoic acid supplementation to marine algae-adapted and unadapted rumen inoculum on the biohydrogenation of unsaturated fatty acids in freeze-dried grass. J. Dairy Sci. 91:1122-1132.

Wang, R. F., W. D. Xie, Z. Zhang, D. M. Xing, Y. Ding, W. Wang, C. Ma, and L. J. Du. 2004. Bioactive compounds from the seeds of Punica granatum (pomegranate). J. Nat. Prod. 67:2096-2098.

Weller, R. A., and A. F. Pilgrim. 1974. Passage of protozoa and volatile fatty acids from the rumen sheep and from a continuous in vitro fermentation system. Br. J. Nutr. 32:341-351. 